\title{
PENGARUH BAURAN PEMASARAN JASA TERHADAP KEPUASAN PENGUNJUNG TAMAN WISATA KAMPOENG RADJA DI KOTA JAMBI
}

\author{
Oleh: \\ Wella Sandria \\ Dosen Tetap STIE Muhammadiyah Jambi \\ wellasandria@gmail.com
}

\section{Ringkasan}

Kegiatan pemasaran pada intinya memfokuskan diri pada produk, penerapan harga, kebijakkan distribusi dan cara promosi, yang dalam hal ini dikenal sebagai bauran pemasaran jasa (marketing mix), dimana berbagai strategi tersebut digunakan untuk memberikan kontribusi terhadap pencapaian tujuan perusahaan yaitu meningkatkan kepuasan pelanggan. Pengumpulan data untuk 256 orang pengunjung dilakukan secara primer melalui pengisian kuesioner dan data tersebut di analisis dengan menggunakan SPSS 23.0. Hasil penelitian ini adalah secara simultan ke tujuh aspek bauran pemasaran yang meliputi product, price, place, promotion, people, process dan physical evidence secara signifikan berpengaruh terhadap kepuasan pengunjung Kampoeng Radja. Akan tetapi, secara parsial hanya aspek promotion, people, process, dan physical evidence yang secara signifikan berpengaruh terhadap kepuasan pengunjung Kampoeng Radja, sementara aspek product, price dan place tidak berpengaruh terhadap kepuasan pengunjung Kampoeng Radja

Keywords : Marketing, Marketing Mix, Customer Satisfaction

\section{PENDAHULUAN}

Perkembangan bisnis pada era globalisasi telah berkembang sangat pesat dan mengalami perubahan yang berkesinambungan. Setiap pelaku usaha di setiap kategori bisnis, dituntut untuk memiliki kepekaan terhadap setiap perubahan yang terjadi dan menempatkan orientasi kepada kepuasan pelanggan sebagai tujuan utama (Kotler, 2007). Bukan hanya bisnis manufaktur, sektor jasa juga mengalami peningkatan yang dramatis yang dikenal sebagai "Great Lorward" atau kemajuan yang luar biasa dalam dunia jasa.

Berdasarkan sifatnya, jasa mempunyai keunikan yaitu sifatnya yang tidak berwujud (intangibility), penyampaian yang bervariasi (variability), proses produksi dan konsumsi yang dilakukan bersamaan (simultaneity) serta tidak tahan lama (imperishability). Hal tersebut memiliki esensi utama yaitu perlunya keterlibatan secara langsung karyawan dalam delivery process, sehingga peran karyawan menjadi ujung tombak keberhasilan jasa. Keberhasilan lain dalam memasarkan jasa juga sangat ditentukan oleh sejauh mana atribut bauran pemasaran jasa (service marketing mix) dalam memuaskan keinginan, kebutuhan dan harapan pelanggan. 
Dalam penelitiannya yang lebih dari 35 tahun yang lalu, Peter Drucker telah menyatakan bahwa tugas utama perusahaan adalah "menciptakan pelanggan". Namun, pelanggan masa kini menghadapi beraneka ragam pilihan produk, merek, harga dan pemasok. Pelanggan selalu ingin memaksimalkan nilai dan membentuk suatu harapan nilai dan bertindak atas dasar harapan tersebut untuk dapat mencapai kepuasan mereka dalam menggunakan produk perusahaan.

PT. Anjungan Buana Wisata atau yang lebih dikenal sebagai Taman Wisata Kampoeng Radja (KR) Jambi merupakan tempat rekreasi keluarga, karena seluruh wahana maupun fasilitas dapat dinikmati oleh seluruh kalangan; mulai anak - anak, remaja, dewasa hingga usia lanjut. Sejak di buka tanggal 1 April 2006 pengunjung Kampoeng Radja terus meningkat. Tahun 2016 pengunjung berkisar antara 13.000 - 15.000 orang perbulan. Pengunjung berasal dari seluruh Kabupaten/Kota di Provinsi Jambi dan kota-kota besar di luar Provinsi Jambi. Pengunjung mancapai puncak (peak season) di hari Sabtu dan Minggu atau pada hari-hari libur. Untuk melayani dan mencapai kepuasan pengunjung taman ini diperlukan optimalisasi pengelolaan bauran pemasaran dan peran karyawan yang memiliki kinerja (performance) baik dari berbagai aspek.

Salah satu yang menjadi bahasan penelitian ini adalah melihat secara parsial dan simultan pengaruh unsur bauran pemasaran jasa terhadap kepuasan pengunjung di Taman Wisata Kampoeng Radja Jambi. Permasalahan yang perlu mendapat perhatian dalam upaya untuk meningkatkan kepuasan pengunjung di Kampoeng Radja Jambi adalah pengelolaan unsur - unsur bauran pemasarannya. Dilihat dari aspek bauran pemasarannya, Kampoeng Radja memiliki beragam produk wahana permainan yang digemari masyarakat Jambi mulai dari permainan untuk anak - anak, remaja dan orang tua. Keberagaman wahana tersebut terus berganti dalam kurun waktu lima tahun sekali untuk dapat menekan angka kejenuhan pengunjung. Harga yang ditawarkan untuk dapat menikmati seluruh wahana tidak tergolong mahal dan masih terjangkau oleh ekonomi masyarakat Jambi dan pengunjung luar Jambi, bahkan terdapat penawaran untuk harga paket edukasi dan penyewaan aula indoor dan outdoor untuk berbagai acara. Lokasi Kampoeng Radja yang sangat strategis berada di tengah kota dan di pinggir jalan dengan akses jalan aspal yang lebar akan memudahkan pengunjung untuk datang menghabiskan waktu santai dan liburan bersama keluarga. Media promosi yang digunakan taman wisata ini sangat beragam mulai dari media massa, media cetak, media elektronik, media sosial hingga kerjasama dengan beberapa vendor seperti Tribun Family Card 
dan lain sebagainya. Untuk dapat melayani para pengunjung baik di hari biasa maupun di musim puncak keramaian, Kampoeng Radja memiliki tenaga kerja yang siap pakai, ahli, pengetahuan tinggi dan berpengalaman di bidangnya sehingga pengunjung merasa puas. Proses penyampaian jasa sangat akrab, ramah dan santun. Beberapa fasilitas fisik yang ada di Kampoeng Radja seperti lahan parkir kendaraan yang memadai, perpaduan warna yang menarik, fisik wahana yang selalu diperbarahui, desain interior, music, susunan dan tata letak wahana, kerapian dan kebersihan seragam karyawan, dan lainnya juga sangat mendukung tercapainya kepuasan pengunjung.

Dengan pelayanan yang baik dan pengelolaan setiap unsur bauran pemasaran maka Taman Wisata Kampoeng Radja dapat meningkatkan kepuasan pengunjung yang tentunya akan berdampak pada pengulangan kedatangan pengunjung. Selain hal tersebut dapat membantu memenangkan persaingan, juga dapat meningkatkan penjualan.

\section{Bauran Pemasaran (MarketingMix)}

Istilah bauran pemasaran digunakan pertama kali oleh Neil Borden pada tahun 1964. Borden menyusun daftar elemen bauran pemasaran yang terdiri atas 12 aspek, yaitu Product Planning, Pricing, Branding, Channels of Distribution, Personal Selling, Advertising, Promotions, Packaging, Display, Servicing, Physical Handling dan Fact Finding and Analysis. Daftar tersebut kemudian disederhanakan dan dipopulerkan oleh Jerome McCarthy pada tahun 1968 ke dalam empat aspek pokok yaitu Product, Price, Place, dan Promotion, yang kemudian dikenal dengan istilah 4P. Sebagai dasar pertimbangan pengambilan keputusan dalam pembuatan strategi komunikasi pemasaran, menurut Lovelock, dkk (2011) bahwa bauran pemasaran tradisonal 4P tidak melibatkan unsur antar muka dengan konsumen (customer interface), sehingga diperlukan perluasan terhadap konsep 4P menjadi 7P dengan menambahkan penyedia jasa / orang (people), proses (process) dan, bukti fisik (physical evidence). Penambahan unsur bauran pemasaran jasa dilakukan antara lain karena jasa memiliki karakteristik yang berbeda dengan produk, yaitu tidak berwujud, tidak dapat dipisahkan, beraneka ragam dan mudah lenyap.

Bauran pemasaran yaitu" marketing mix defined as the elemens an organizations controls that can be used to satisfy or communicate with customer - Bauran pemasaran jasa adalah elemen organisasi perusahaan yang dapat dikontrol perusahaan dalam melakukan komunikasi dengan konsumen dan akan dipakai untuk memuaskan”. Selanjutnya, menurut Kotler dan Amstrong (2012) "marketing mix is good marketing tool is a set of products, pricing, 
promotion, distribution, combined to produce the desired response of the target market Bauran pemasaran adalah perangkat pemasaran yang baik yang meliputi produk, penentuan harga, promosi, distribusi, digabungkan untuk menghasilkan respon yang diinginkan pasar sasaran" (Zeithaml and Bitner : 2001).

Bauran pemasaran dan keputusan konsumen berkaitan sangat erat (Tjiptono, 2002). Bauran pemasaran memberikan suatu dorongan kepada konsumen untuk menjalin ikatan hubungan yang kuat dengan perusahaan. Dalam jangka panjang ikatan seperti ini memungkinkan perusahaan untuk memahami dengan seksama harapan konsumen serta kebutuhan mereka. Dengan demikian perusahaan dapat meningkatkan keputusan pelanggan dimana perusahaan memaksimumkan pengalaman yang menyenangkan dan meminimumkan atau meniadakan pengalaman konsumen yang kurang menyenangkan. Pada gilirannya kepuasan konsumen dapat menciptakan kesetiaan atau loyalitas pelanggan kepada perusahaan.

\section{PRODUK (PRODUCT)}

Produk menurut Kotler (2002) merupakan segala sesuatu yang dapat ditawarkan produsen untuk diperhatikan, diminta, dicari, dibeli, digunakan, atau dikonsumsi pasar sebagai pemenuhan kebutuhan atau keinginan pasar.

\section{HARGA (PRICE)}

Menurut Kotler (2002) harga (price) adalah sejumlah uang yang dibebankan untuk sebuah produk atau jasa. Informasi tentang harga yang dimiliki oleh seorang konsumen memberikan persepsi awal terhadap kualitas jasa yang akan mereka terima oleh konsumen.

\section{TEMPAT (PLACE)}

Keputusan mengenai tempat, lokasi dan lingkungan pelayanan yang akan digunakan dalam penyampaian jasa kepada konsumen sebagai bagian dari nilai dan manfaat dari jasa.

\section{PROMOSI (PROMOTION)}

Promosi dilakukan pemasar untuk dapat menjelaskan dan mempromosikan nilai dari jasa, yaitu periklanan, promosi penjualan, penjualan personal, pemasaran langsung, dan hubungan masyarakat. (Lovelock dkk, 2011).

\section{PENYEDIA JASA (PEOPLE)}

Menurut Zeithaml and Bitner (2000), orang (people) adalah semua pelaku atau sumber daya manusia yang memainkan peranan dalam penyajian jasa sehingga dapat mempengaruhi persepsi pembeli.

\section{PROSES (PROCESS)}


Menurut Payne (2000) yaitu tindakan menciptakan dan memberikan jasa pada pelanggan dimana mereka akan merasakan sistem pemberian jasa tersebut meliputi semua prosedur aktual, mekanisme, dan aliran aktivitas dalam menyampaikan jasa.

\section{BUKTI FISIK (PHYSICAL EVIDENCE)}

Bukti fasilitas fisik (physical evidence) merupakan lingkungan atau tampilan fisik dari perusahaan yang menunjukkan tempat dan dimana jasa diberikan. Seperti penampilan gedung, toko, brosur, interior toko, fasilitas toko, musik sebagai back ground transaksi dan lain - lain.

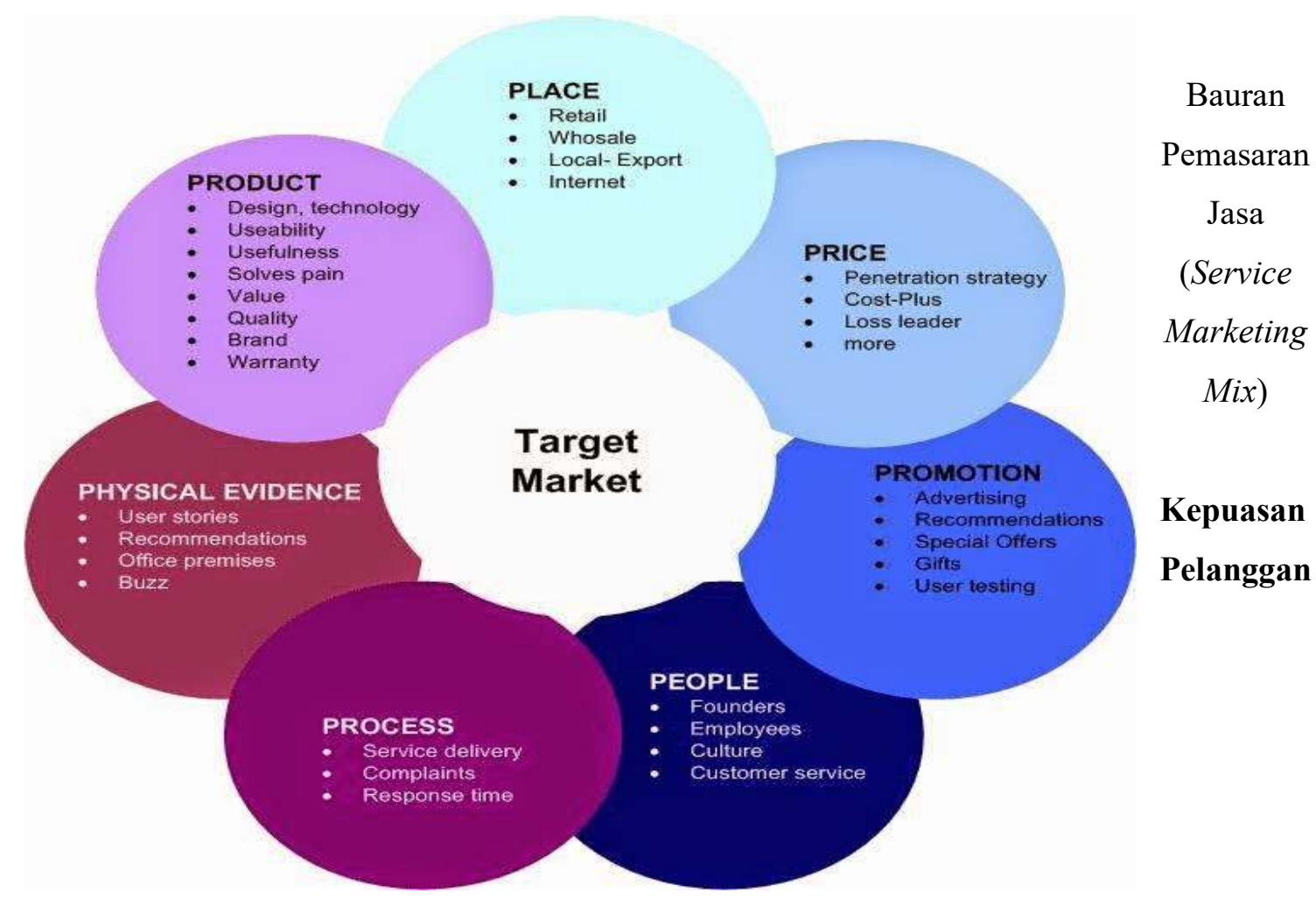

\section{(Customer's Satisfaction)}

Kepuasan pelanggan adalah perasaan senang atau kecewa seseorang sebagai hasil dari perbandingan antara prestasi produk yang dirasakan dan yang diharapkannya (Kotler, 1997). Defenisi kepuasan menurut Zeithaml dan Bitner (2003) adalah: "Satisfaction is the customers evaluation of product or service in terms of whether that product or service has meet their needs and expectations". Kepuasan adalah evaluasi konsumen terhadap produk.

Kepuasan pelanggan merupakan ukuran untuk mengetahui kualitas jasa yang ditawarkan oleh perusahaan, dengan membandingkan harapan dengan kinerja jasa yang dirasakan. Jika kepuasan pelanggan dapat tercapai, berarti kualitas jasa yang ditawarkan dapat memenuhi 
harapan konsumen. Sehingga menyebabkan konsumen melakukan pembelian ulang dan akhirnya akan terjadi peningkatan penjualan.

\section{METODOLOGI PENELITIAN}

Penelitian ini merupakan penelitian korelasional, sedangkan pendekatan penelitian yang digunakan dalam penelitian ini adalah kuantitatif deskriptif karena dalam prosedur dan analisisnya peneliti menggunakan analisis statistik dan pendekatan studi kasus. Melalui kajian ini peneliti akan menggambarkan pengaruh bauran pemasaran jasa terhadap kepuasan pengunjung Taman Wisata Kampoeng Radja di Kota Jambi.

Dalam penelitian ini penulis menggunakan jenis data primer dimana data diperoleh langsung dari sumbernya, yaitu kuisinoner, observasi, wawancara dengan pengunjung. Kuesioner dilakukan dengan cara memberikan seperangkat pertanyaan dan pernyataan tertulis kepada respoden untuk di jawab. Skala pengukuran untuk semua indikator pada masing masing variabel menggunakan skala Likert (skala 1 sampai skala 5), di mulai dari Sangat Tidak Setuju (STS), Tidak Setuju (TS), Kurang Setuju (KS), Setuju (S) dan Sangat Setuju (SS). Untuk mendapatkan data kuantitatif, digunakan skala Likert yang digolongkan ke dalam lima tingkatan sebagai berikut (Sugiyono, 2004) :

a. Untuk jawaban a sangat tidak setuju di beri nilai $=1$.

b. Untuk jawaban b tidak setuju di beri nilai $=2$.

c. Untuk jawaban c kurang setuju di beri nilai $=3$.

d. Untuk jawaban d setuju di beri nilai $=4$.

e. Untuk jawaban e sangat setuju di beri nilai $=5$.

Sumber data primer dalam penelitian ini adalah para pengunjung Taman Wisata Kampoeng Radja Jambi. Sedangkan data sekunder diambil dari kajian pustaka dan karya ilmiah yang mendukung tema penelitian. Sedangkan untuk melakukan analisis data dilakukan dengan menggunakan metode Analisis Regresi Linier Berganda. Model regresi adalah model yang digunakan untuk menganalisis pengaruh dari variabel independen terhadap variabel dependen (Sugiyono, 2004).

\section{HASIL PENELITIAN}

Hasil analisis statistik deskriptif untuk demografi pengunjung Taman Wisata Kampoeng Radja menunjukkan bahwa jumlah responden dalam penelitian sebanyak 256 orang, yang terdiri dari 78 orang (30.5\%) berjenis kelamin laki-laki dan 178 orang $(69.5 \%)$ berjenis kelamin perempuan. Responden yang berusia kurang dari 20 tahun sebanyak 148 orang 
(57.8\%), usia 20-30 tahun sebanyak 72 orang (28.1\%), usia 30-40 tahun sebanyak 29 orang (11.3\%), usia 40-50 tahun sebanyak 8 orang (2.3\%), dan yang berusia $25-35$ tahun sebanyak 1 orang $(0.4 \%)$. Sebanyak 195 orang responden belum menikah $(76.2 \%)$ dan sisanya sebanyak 61 orang (23.8\%) sudah menikah. Sebanyak 205 responden berasal dari Jambi $(80.1 \%)$ dan 51 orang (19.9\%) berasal dari luar Provinsi Jambi.

Setelah dilakukan uji validitas terhadap item pertanyaan masing - masing variabel, diketahui bahwa semua variabel yang digunakan dalam penelitian mempunyai nilai sig2-tailed indikator memiliki nilai lebih kecil daripada nilai signifikansi 5\% $(0,05)$ yaitu , sehingga kuisioner yang digunakan dalam penelitian dinyatakan valid. Hasil pengujian reliabilitas juga menunjukkan bahwa semua variabel dalam penelitian mempunyai koefisien Cronbach Alpha yang cukup atau memenuhi kriteria untuk dikatakan reliabel yaitu di atas 0,5 , sehingga untuk item-item pada masing-masing variabel tersebut layak digunakan sebagai alat

Model Summary Regresi Berganda

\begin{tabular}{|l|r|r|r|r|r|}
\hline & & & \multicolumn{1}{c|}{ Model Summary } \\
Model & $\mathrm{R}$ & $\mathrm{R}$ Square & \multicolumn{1}{c|}{$\begin{array}{c}\text { Sdjuare } \\
\text { Square }\end{array}$} & $\begin{array}{c}\text { Std. Error of the } \\
\text { Estimate }\end{array}$ & Durbin-Watson \\
\hline 1 & $.819^{\mathrm{a}}$ & .671 & .662 & .476 & 1.932 \\
\hline
\end{tabular}

a. Predictors: (Constant), PE, Price, Product, People, Place, Process, Promotion

b. Dependent Variable: CS

Tabel di atas menunjukkan bahwa nilai koefisien determinasi atau R Square yaitu sebesar 0.671 yang artinya sebesar $67.1 \%$ variability variabel kepuasan pengunjung mampu dijelaskan oleh variabel product, price, place, promotion, people, process dan physical evidence. Sedangkan sisanya 32.9\% dijelaskan oleh variabel lainnya yang tidak masuk dalam variabel penelitian ini.

Uji ANOVA Regresi Berganda

ANOVA $^{\mathrm{a}}$

\begin{tabular}{|ll|r|r|r|r|r|}
\hline Model & & Sum of Squares & df & Mean Square & F & Sig. \\
\hline 1 & Regression & 114.713 & 7 & 16.388 & 72.249 & $.000^{\mathrm{b}}$ \\
& Residual & 56.252 & 248 & .227 & & \\
& Total & 170.965 & 255 & & & \\
\hline
\end{tabular}

a. Dependent Variable: CS

b. Predictors: (Constant), PE, Price, Product, People, Place, Process, Promotion 


\begin{tabular}{|c|c|c|c|c|c|c|}
\hline \multicolumn{7}{|c|}{$\begin{array}{l}\text { Koefisien Regresi Berganda } \\
\text { Coefficients }^{\mathbf{a}}\end{array}$} \\
\hline \multirow{2}{*}{\multicolumn{2}{|c|}{ Model }} & \multicolumn{2}{|c|}{ Unstandardized Coefficients } & \multirow{2}{*}{$\begin{array}{c}\text { Standardized } \\
\text { Coefficients } \\
\text { Beta }\end{array}$} & \multirow[b]{2}{*}{$\mathrm{t}$} & \multirow[b]{2}{*}{ Sig. } \\
\hline & & $\mathrm{B}$ & Std. Error & & & \\
\hline \multirow[t]{8}{*}{1} & (Constant) & .010 & .191 & & .050 & .960 \\
\hline & Product & .062 & .052 & .060 & 1.180 & .239 \\
\hline & Price & .046 & .047 & .046 & .972 & .332 \\
\hline & Place & -.036 & .053 & -.038 & -.674 & .501 \\
\hline & Promotion & .186 & .063 & .187 & 2.961 & .003 \\
\hline & People & .120 & .064 & .116 & 1.876 & .062 \\
\hline & Process & .197 & .064 & .190 & 3.092 & .002 \\
\hline & $\mathrm{PE}$ & .423 & .064 & .388 & 6.609 & .000 \\
\hline
\end{tabular}

a. Dependent Variable: CS

Hasil statistik uji F menunjukkan nilai p-value sebesar $0.000(<0.05)$ yang berarti secara simultan variabel independen yaitu variabel product, price, place, promotion, people, process dan physical evidence secara signifikan. Sedangkan, hasil uji t menunjukkan bahwa nilai $p$ value untuk variabel promotion, process dan physical evidence adalah 0.003, 0.002, dan 0.000 $(<0.05)$ sehingga ketiga variabel tersebut secara signifikan berpengaruh terhadap kepuasan pengunjung. Variabel people memiliki p-value $0.062(<0.10)$, artinya secara signifikan berpengaruh terhadap kepuasan pengunjung dengan Alpha 10\%. Sedangkan variabel product, price dan place memiliki $p$-value $0.239,0.332,0.501(>0.05$ atau $>0.10)$ artinya ketiga variabel tidak berpengaruh terhadap kepuasan.

\section{KESIMPULAN}

Variabel physical evidence berpengaruh positif dan signifikan terhadap kepuasan konsumen. Arah positif ini menunjukkan bahwa kenaikan variabel physical evidence akan diikuti oleh kenaikan variabel kepuasan konsumen. Physical evidence yaitu bukti fisik adalah komponen utama dalam membentuk kesan sebuah perusahaan. Hasil penelitian ini sesuai dengan teori yang ada, bahwa physical evidence (bukti fisik) berpengaruh positif terhadap kepuasan konsumen. Bukti fisik (physical evidence) memiliki peranan penting untuk menarik minat konsumen agar datang ke suatu perusahaan atau tempat usaha dan melakukan pembelian. Hal ini sesuai dengan pendapat Luppiyoadi (2013) bahwa bukti fisik (physical evidence) adalah lingkungan fisik perusahaan tempat jasa diciptakan dan tempat penyedia jasa dan 
konsumen berinteraksi, ditambah elemen tangible yang diinginkan untuk mengkomunikasikan atau mendukung peranan jasa itu.

Adapun kesimpulan akhir dari penelitian ini adalah secara simultan ke tujuh aspek bauran pemasaran yang meliputi product, price, place, promotion, people, process dan physical evidence secara signifikan berpengaruh terhadap kepuasan pengunjung Kampoeng Radja. Akan tetapi, secara parsial hanya aspek promotion, people, process, dan physical evidence yang secara signifikan berpengaruh terhadap kepuasan pengunjung Kampoeng Radja, sementara aspek product, price dan place tidak berpengaruh terhadap kepuasan pengunjung Kampoeng Radja.

\section{DAFTAR PUSTAKA}

Abdullah, T. \& Francis, T. (2016). Manajemen Pemasaran. Edisi Pertama. Jakarta : PT. Rajawali Press.

Amilia, S. \& Novianti, A. (2016). Pengaruh Bauran Pemasaran Terhadap Kepuasan Konsumen Pada Warung Kanasha di Kota Langsa. Jurnal Manajemen dan Keuangan. Vol.5 (1).467-468.

Haksever et al. (2000). Service Management

Kotler, Philip. (1997). Marketing Management. $9^{\text {th }}$ Edition. New Jersey : Prentice Hall International Inc.

Kotler, P. (2000). Manajemen Pemasaran. Edisi Millenium. Jakarta : PT. Prenhallindo.

Kotler, P. (2002). Manajemen Pemasaran. Edisi Millenium. Jilid 2. Jakarta : PT. Prenhallindo.

Kotler, P. (2007). Manajemen Pemasaran. Jakarta : PT. Mancanan Jaya Cemerlang.

Kotler, P. \& Keller,K,L. (2008). Manajemen Pemasaran, Edisi 13. Jakarta. Erlangga.

Kotler, P. \& Keller,K,L. (2009). Manajemen Pemasaran. Jilid 1 dan 2. Edisi 13. Jakarta : Erlangga.

Kotler, P. \& Amstrong, G. (2012). Prinsip - Prinsip Pemasaran. Edisi 13. Jilid 1. Jakarta : Erlangga.

Lovelock, et. al. (2011). Service Marketing : People, Technology and Strategy. 7th Edition. USA : Prentice Hall.

Lupiyoadi, R. (2013). Manajemen Pemasaran Jasa Berbasis Kompetensi. Edisi 3. Jakarta : Salemba Empat. 
Mary, J, B., Valerie, A. \& Zeithaml. (2000). Service Marketing. 2nd Edition on International Edition. McGraw Hill Companies Inc.

Payne, A. (2001). The Essence of Service Marketing. Diterjemahkan oleh Fandy Tjiptono. Yogyakarta : Penerbit Andi.

Payne, A. (2000). Pemasaran Jasa. The Essence of Service Maerketing. Yogyakarta. Penerbit Andi.

Setianingsih, W.E. (2017). Pengaruh Bauran Pemasaran Jasa Terhadap Kepuasan Konsumen Pada Pondok Angkringan Kang Teek Jember. Jurnal Manajemen dan Bisnis Indonesia. Vol 3 (1). 18-30.

Sugiyono. (2004). Metode Penelitian Bisnis. Bandung : Alfabeta.

Sugiyono. (2011). Statistika Untuk Penelitian. Bandung : Alfabeta.

Suwardi, E. (2010). Metodologi Penelitian : Folklor, Konsep, Teori dan Aplikasi. Yogyakarta. Media Presindo.

Tjiptono, F. (2002). Manajemen Jasa. Yogyakarta : Penerbit Andi.

Tjiptono, F. (2010). Strategi Pemasaran. Edisi 3. Yogjakarta : Penerbit Andi.

Zeithaml, V.A. \& M.J. Bitner. (20010. Service Marketing : Integrating Customer Focus Across the Firm. International Edition. McGraw - Hill . United Stated of America.

Zeithaml, V, A. \& Marry J, B. (2003). Third Edition. Service Marketing :Integrating Customer Focus Across the Firm. International Edition. McGraw - Hill Companies Inc. 